\title{
A FAMÍLIA COMO BASE DA CONSTITUIÇÃO DE CRENÇAS E VALORES SEXUAIS
}

Maria Luiza Macedo de Araújo ${ }^{1}$

\section{THE FAMILY AS THE FOUNDATION OF THE CONSTITUTION OF BELIEFS AND VALUES OVE}

Resumo: A família é o primeiro núcleo de formação de crenças e valores do ser humano e, como tal, desempenha um importante papel no desenvolvimento de sua sexualidade, porém está exposta às mais variadas influências no mundo atual. Discute-se a formação de crenças, atitudes e valores como norteadores do comportamento sexual. A família atual é vista em contraposição à família tradicional. Abordam-se as influências sócio-culturais na formação de crenças e valores, a aprendizagem social e a como a sexualidade pode ser uma importante parte de todo o seu desenvolvimento futuro.

Palavras-chave: Família; crenças e valores; cultura e sexualidade; aprendizagem social.

Abstract: The family is the first nucleus of formation of beliefs and values of human being and, as such, play an important role in the development of its sexuality, however it is displayed to the most varied influences in the current world. It is argued formation of beliefs, attitudes and values as guides of the sexual behavior. The current family is seen in contraposition the traditional family. The approach includes the sociocultural influences in the formation of beliefs and values, the social learning and the sexuality as an important part of the child future development

Keywords: Family; beliefs and values; culture; sexuality; social learning.

1 Psicóloga. Mestre em Psicologia. Doutora em Filosofia. e-mail: luaraujo.rlk@terra.com.br 


\section{Introdução}

Para entendermos a criança e sua formação de crenças e valores é necessário ir além da díade mãe/filho ou pai/filho e do triângulo pai/mãe/filho. Embora seja de primordial importância a relação familiar para o desenvolvimento infantil, não se pode esquecer que a família está inserida numa dinâmica social e cultural mais ampla, sujeita às mais diversas influências.

Segundo FISHBEIN E AJZEN (1975) e AJZEN E FISHBEIN (1980) o comportamento é o resultado das crenças individuais e sociais do sujeito e estas se formam a partir de sua interação com o meio ambiente interno e externo. Ao nascer, a criança encontrará uma família que lhe dará afeto e os primeiros cuidados essenciais para seu desenvolvimento. Mas isto é apenas o básico para que ela sobreviva. A relação familiar também será influenciada pelo novo ser agora pertencente a ela. A sua chegada, se for o(a) primogênito (a), ou se tiver irmãos(ãs) mais velhos(as) afetará a dinâmica familiar, a relação marido/mulher que sofrerá uma desorganização para depois se acomodar e encontrar seu novo equilíbrio (BEE, 1996). O trabalho discute a importância da família como formadora de crenças e valores sexuais, abordando as diversas possibilidades de constituição do núcleo familiar atual nas suas diferentes formas de existir e relaciona a sociedade e a cultura como elementos que podem afetar a família em sua interação com o meio, considerando-se o mundo atual globalizado.

\section{Desenvolvimento}

Em primeiro lugar, é preciso conceituar a que família a criança pertence: se é a tradicional heterossexual e no primeiro casamento; se é uma família na qual um ou os dois membros são recasados; se há filhos de outros matrimônios; se é uma família constituída por duas pessoas do mesmo sexo, ou ainda de apenas um genitor ou parente. Portanto, quando falamos em família, precisamos saber a que família estamos nos referindo, pois as crenças e os valores vivenciados podem ser muito diferentes, a diversidade começa exatamente no núcleo familiar (FÉRES-CARNEIRO, 1998).

Segundo FISHBEIN E AJZEN (1975) e AJZEN E FISHBEIN (1980), as crenças individuais são formadas a partir da percepção interna e externa de tudo que nos rodeia. Estas crenças formarão atitudes positivas ou negativas em relação a algum objeto ou comportamento. Porém, os autores citados vão mais além e identificam as crenças normativas, que são aquelas formadas 
pelos referentes sociais (pai, mãe, irmãos, amigos, religião, meios de comunicação e tudo mais que a sociedade e a cultura nos informam). A importância dos referentes sociais para nós irá formar a norma subjetiva que, junto com nossas atitudes formarão uma intenção que originarão um comportamento conseqüente. Este comportamento dará feedback para nossas crenças individuais e normativas, que irá repetir o ciclo alterando ou solidificando um comportamento. Este é um modelo informacional e pressupõe a interação social como uma parte da constituição das crenças do sujeito. Além disso, prevê que as vivências podem modificar ou não nossa conduta. A família, então, como o primeiro contato social da criança estará na base da formação de suas crenças. Estas crenças se organizarão num sistema psicológico e, não necessariamente lógico, que formarão o "sistema de crenças individual" de cada sujeito (ROKEACH, 1981).

A sexualidade, inerente ao ser humano, como parte da sua natureza também será formada de crenças e valores absorvidos e percebidos a partir de tudo que o rodeia e de tudo que ele vivencia (MARÍAS, J. 1971). ORTEGA Y GASSET (1973) tem uma frase que se tornou célebre: “[...] eu sou eu e minha circunstância”, significando que o sujeito é toda a sua história de vida e vivência atual, ou seja

[...] "vida, no sentido biográfico e não biológico - se por biologia se entende a psicossomática, - vida é encontrar-se alguém a quem chamamos homem (como poderíamos e talvez devêssemos chamar X, -. ...) tendo de ser na circunstância do mundo. Nosso ser, porém enquanto "se na circunstância", não é quieto e meramente passivo. Para ser, isto é, para continuar sendo, tem de estar sempre fazendo algo, mas isso que há de fazer não lhe é imposto nem pré-fixado; antes há de escolhe-lo, há de decidir, intransferivelmente, por si e diante de si, sob sua exclusiva responsabilidade".

Do que foi dito, argumenta-se que a criança constrói sua história, sua vida a partir das interaçôes com a família, pois é o primeiro núcleo social, porém mantém sua individualidade e sob os mesmos estímulos, indivíduos diferentes formarão sistemas de crenças individuais. É que FISHBEIN E AJZEN (1975) problematizam na formação da norma subjetiva.

Se abordarmos a Teoria dos Sistemas (BEE, 1996), veremos que os diversos sistemas que compõem o universo do sujeito são organizados de forma em que o todo é maior que a soma das partes, ou seja, como uma melodia é composta de notas musicais, mas é mais que a soma das mesmas, o todo consiste das partes do relacionamento do sujeito com o mundo, mas é mais que apenas partes. $\mathrm{O}$ relacionamento familiar entra como uma das partes que compõe o todo maior que éo seu sistema individual. Quando há mudança 
em uma parte, as outras são afetadas, mas se organizam dentro desta nova realidade, da mesma forma que Piaget concebe o sistema cognitivo da criança.

BEE menciona a Abordagem Ecológica de BROFENBRENNER (1979, 1989, apud BEE, 1996), na qual o sistema ecológico em que a criança se desenvolve é composto de camadas ou círculos concêntricos, cuja camada mais central é composta de todos os ambientes que a criança está em contato - primeiramente a família, depois a escola ou creche. A seguir vêm os outros sistemas que irão constituir as vivências do sujeito, como trabalho, círculo de amigos e, mais externamente, todas as diversidades culturais. Assim, embora as primeiras crenças sejam formadas na família, esta não é sua única fonte de aquisição.

Temos ainda que considerar os valores, pois valor é tudo o que vale para o sujeito, ou seja, que tem um significado maior e mais profundo. Desta forma dizemos "sistema de crenças e valores", pois as diversas crenças estão organizadas de uma forma toda peculiar para cada um e com diferentes configuraçōes (ARAÚJO, 1997).

Abordando especificamente o sistema de crenças e valores sexuais, é na família que a criança terá as primeiras vivências de carinho, afeto, toque, amor, compreensão ou então, rejeição, distanciamento, desamor. Cada família é um microcosmo que será afetado pelas vivências de seus constituintes - uma criança, ao nascer, pode trazer felicidade, alegria, preocupação, decepção, enfim, pode haver muitos sentimentos opostos latentes no lar que a recebe. Este lar pode ser composto de pessoas que se amam ou não, pode ser composto de um casal de sexos opostos ou do mesmo sexo (FÉRESCARNEIRO, 1998), pode ser composto por apenas um genitor ou parente mais próximo. Os limites podem ser claramente colocados para a criança ou não. Ela pode ter a capacidade de desenvolver-se de forma harmoniosa ou não. As vivências acerca da sexualidade podem estar num continuum que vai da extrema repressão até a extrema liberalidade, com total falta de limites.

É na família que acontecem abusos sexuais em relação à criança (podendo ser cometido pelo genitor, padrasto, ou outros parentes, geralmente) e esses abusos podem deixar marcas profundas que irão acompanhar o sujeito por grande parte de sua vida, o que não significa que todas as pessoas abusadas terão problemas futuros, mas é grande a probabilidade (SAFFIOTI, apud RIBEIRO, 1999). A violência doméstica é outra fonte de problemas para uma pessoa que está em desenvolvimento, pois terá a visão no próprio lar de 
violência e impotência em relação ao (à) agressor(a) (ARAÚJO, 2000; SANDI E ARAÚJO, 2000).

Porém, também existem lares em que o amor e a compreensão são vivenciados em sua plenitude, nos quais há diálogo entre pais e filhos, em que os limites são colocados de forma a acompanhar a realidade da criança e a possibilidade de sua adaptação à sociedade sem deixar de se afirmar.

Um outro fato importante a ser considerado é a religião praticada ou não pelos pais, pois algumas famílias estão presas a religiōes altamente repressoras em relação à sexualidade e os pais podem passar esta carga de repressão aos filhos. Porém, cada sujeito irá absorver o que lhe é passado de forma totalmente individual e, em outros lares a religião é vivenciada de forma não repressora (ARAÚJO, 1997).

A mídia é outra fonte de formação de atitudes e de aprendizagem social, pois está presente em quase todas as facetas da vida atual e irá influenciar os pais que, por sua vez, estarão na área de maior relevância para a criança. Então, não é tão simples dizer que a família influencia a criança, pois existe uma interdependência e interatividade cada vez maior entre os seres humanos no mundo globalizado. Hoje, o lar não é um núcleo isolado, mas está em constante interação com as diferentes forças sociais e o grande desafio é não se deixar levar por elas. Portanto, é necessário que o núcleo familiar esteja consciente do seu papel de formador de crenças e valores de forma geral, e em especial, o sistema sexual que o indivíduo irá desenvolver ao longo da vida, tendo um posicionamento crítico, para que não se deixe levar por modismos ou apelos da mídia.

\section{Considerações finais}

Vimos que a sexualidade é uma parte inerente à vivência plena de um indivíduo e que se forma junto com as demais instâncias do mesmo. A criança não é um ser amorfo que é moldado pelo meio ambiente, seguindo tudo o que os pais lhe ensinam. A individualidade é característica do ser humano e é a sua própria humanidade. Cada pessoa formará seu sistema de crenças e valores de acordo com o que lhe for passado, mas absorvendo de modo totalmente subjetivo e característico de sua personalidade. A sua identidade, a auto-imagem, a auto-estima são partes de um todo maior que é o seu modo de pensar e agir. Portanto a constituição das crenças e valores será, em primeiro lugar, vivenciada na família, mas se abrirá para a sociedade, mantendo o núcleo básico de sua existência. 


\section{Referências bibliográficas}

AJZEN, I.; FISHBEIN, M. Understanding attitudes and predicting social behavior. Englewood Cliffs N. J.: Prentice-Hall, Inc., 1980.

ARAÚJO, M.L.M. Sexo e moralidade: o prazer como transgressão no pensamento católico. Londrina: UEL, 1997.

Violência sexual e mulher In: VIII SIMPÓSIO BRASILEIRO DE PESQUISA E INTERCÂMBIO CIENTÍFICO DA ANPEPP. Anais. Serra Negra, 2000,

BEE, H. A criança em desenvolvimento. Porto Alegre: Artes Médicas, 1996.

FÉRES-CARNEIRO, T. Casamento contemporâneo: o difícil convívio da individualidade com a sexualidade. Psicologia: Reflexão e Crítica, V. 11, n. 2. Porto Alegre, 1998.

FISHBEIN, M. \& AJZEN, I. Belief attitude, intention and behavior: an introduction to theory and research. Massachusetts: Addison-Wesley Publishing Company, 1975.

MARÍAS, J. Antropologia metafísica. São Paulo: Duas Cidades, 1971.

ORTEGA Y GASSET, J. O homem e a gente. Rio de Janeiro: Livro IberoAmericano, 1973.

ROCKEACH, M. Crenças, atitudes e valores. Rio de Janeiro: Interciência, 1981.

SAFFIOTTI, H. I. B. As vítimas preferidas da violência de gênero. In: RIBEIRO, M. (org.) O prazer e o pensar. Vol. 1. São Paulo: Gente, 1999.

SANDI, S.F.; ARAÚJO, M.L.M. Violência Doméstica e Sexualidade. Revista Scientia Sexualis. Rio de Janeiro, v. 6, n. 2, p.42 - 54, 2000. 